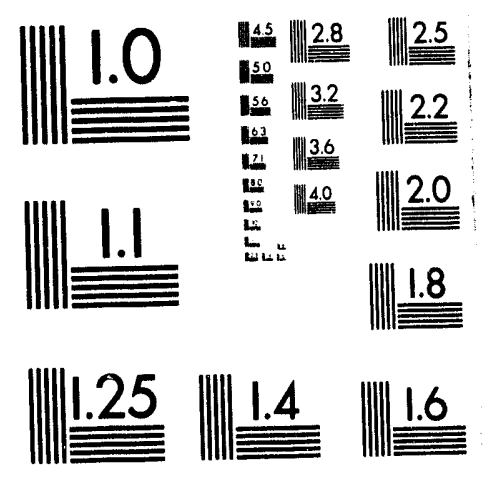



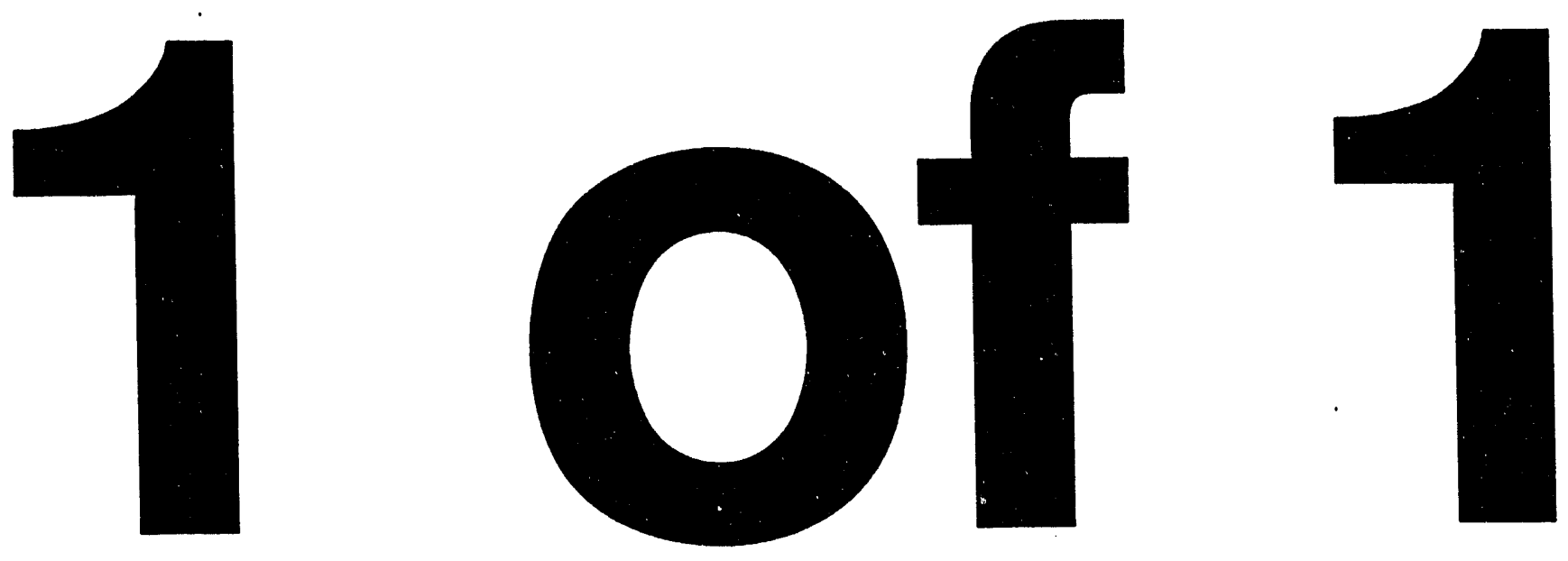


\title{
IMPROVED MACERAL SEPARATION METHOD USING A CONTINUOUS FLOW CENTRIFUGE
}

\author{
Gary R. Dyrkacz and Carol A. A. Bloomquist \\ Chemistry Division, Argonne National Laboratory
}

A new procedure was developed to provide gram to kilogram amounts of highly enriched coal macerals using continuous flow centrifuges. Ninefold enrichments were routinely obtained for various macerals.

In addition to the development of a practical technique for large bench-top maceral separations, this work, funded by the DOE Division of Chemical Sciences, has enabled a richer insight into the dynamics of continuous flow centrifuges. At the same time, Dr. Gary R. Dyrkacz and Carol A. A. Bloomquist, using density gradient centrifugation to monitor the continuous flow separations have been able to develop a general separation model for maceral separations.

\section{DISCLAIMER}

This report was prepared as an account of work sponsored by an agency of the United States This report was prepared as an account of work serther the United States Government nor any agency thereof, nor any of their employees, makes any warranty, express or implied, or assumes any legal liability or responsiemployees, makes any warranty, express or implied, or any information, apparatus, product, or process disclosed, or represents that its use would not infringe privately owned rights. Referprocess disclosed, or represents that its use would not ins, or service by trade name, trademark, ence herein to any specific does not necessarily constitute or imply its endorsement, recommanufacturer, or otherwise does not necessarily constitute or imply its endorsemer the views mendation, or favoring by the United States Government ar any state or reflect those of the and opinions of authors expressed herein do not

United States Government or any agency thereof.

\section{MASTER}




\title{
IMPROVED MACERAL SEPARATION METHOD USING A CONTINUOUS FLOW CENTRIFUGE
}

\author{
Gary R. Dyrkacz and Carol A. A. Bloomquist \\ Chemistry Division, Argonne National Laboratory
}

A detailed study of continuous flow centrifugation applied to maceral separation was conducted. The result was the development of a new routine procedure for the separation of coal macerals. In addition, the research provided new, detailed insights into both the dynamics of continuous flow centrifugation, and a general theory for two phase separations of macerals.

Macerals are the coalified remains of plant parts that can be microscopically observed in coals. All of the organic matter in coals is classified into a number of maceral categories based on color and shape. Because each maceral is derived from different plant parts or different environmental degradations, coal is an exceptionally complex material. This heterogeneity has hindered the understanding of coal structure. Part of the problem has been a lack of efficient methods for separating macerals. The current investigations using continuous flow centrifugation (CFC) to separate macerals were designed to help alleviate this problem.

Continuous flow centrifuges generate a float and sink phase, which can both be removed continuously. The particular centrifuge used here was actually semi- continuous, since only the float phase could be removed continuously.

Analytical density gradient centrifugation (ADGC) was used to monitor the effect of different separation conditions. This high resolution density separation method, pioneered by G. Dyrkacz, permitted not only the measurement of the purity of each separated CFC phase, but also produced a detailed density profile of each phase. The top plot in Figure 1 is an example of a density distribution obtained from a typical bituminous coal. 
The medium chosen for separation was aqueous cesium chloride with the surfactant, Brij-35. This medium, developed for density gradient work, was found to exhibit execeptional separation characteristics in the CFC separations as well."

To optimize the conditions of separation, both the rotor speed and flow rate through the rotor were varied. The purity of the separation changed in a non- linear but monotonic fashion with each parameter. It was not possible to achieve phase purities that were independent of the rotor speed or liquid flow rate indicating complete separation. However, under routine operating conditions, low density macerals could be enriched from $11 \%$ to $93 \%$ in a single separation cycle and to $98 \%$ by recycling the float phases. The sink phases in such separations were somewhat less pure - $84 \%$ pure with one separation cycle, and $90 \%$ pure with a recycle. The lower sink phase purities are believed to be the result of a zone within the rotor, where there is little axial liquid flow, and liquid rotation is below the nominal rotor speed. Figure 1 is an example of the density distributions for phases obtained from two separate separations of the original coal.

The maximum coal concentration that could be processed without significant loss of purity was about 120 grams per liter. Loading studies indicated that the rotor could hold no more than about 60 grams of sink material, before the efficiency deteriorated.

Three high volatile bituminous coals were used in this study. Two were obtained from the Argonne Premium Coal Program and one came from The Pennsylvania State University Coal Bank. Particle dispersion problems were encountered with one of the coals (an Illinois coal) which produced float phase enrichments of $60-74 \%$.

Based on the detailed density profiles of the S/F phases, and considering the theoretcial dynamics of particles in a centrifugal field, a general model for density separations generating two phases was developed. The model predicted that phase purities cannot be constant at all separation densities, but are intimately coupled to the density distribution of the coal sample. The experimental data substantiated this conclusion. 
Multiple separations of single coal samples were also performed. Because many of the fractions derived from the separations were the product of two separations, the purities were understandably lower. From these experiments it was found that the purity of a fraction depends on the size of the density interval used to fractionate the coal: Smaller density intervals lead to

- lower purity fractions. This is a consequence of mass balance considerations, and the separation efficiencies at different densities. No one appears to have previously realized that fraction purities should be a natural consequence of finer density fractionation. 


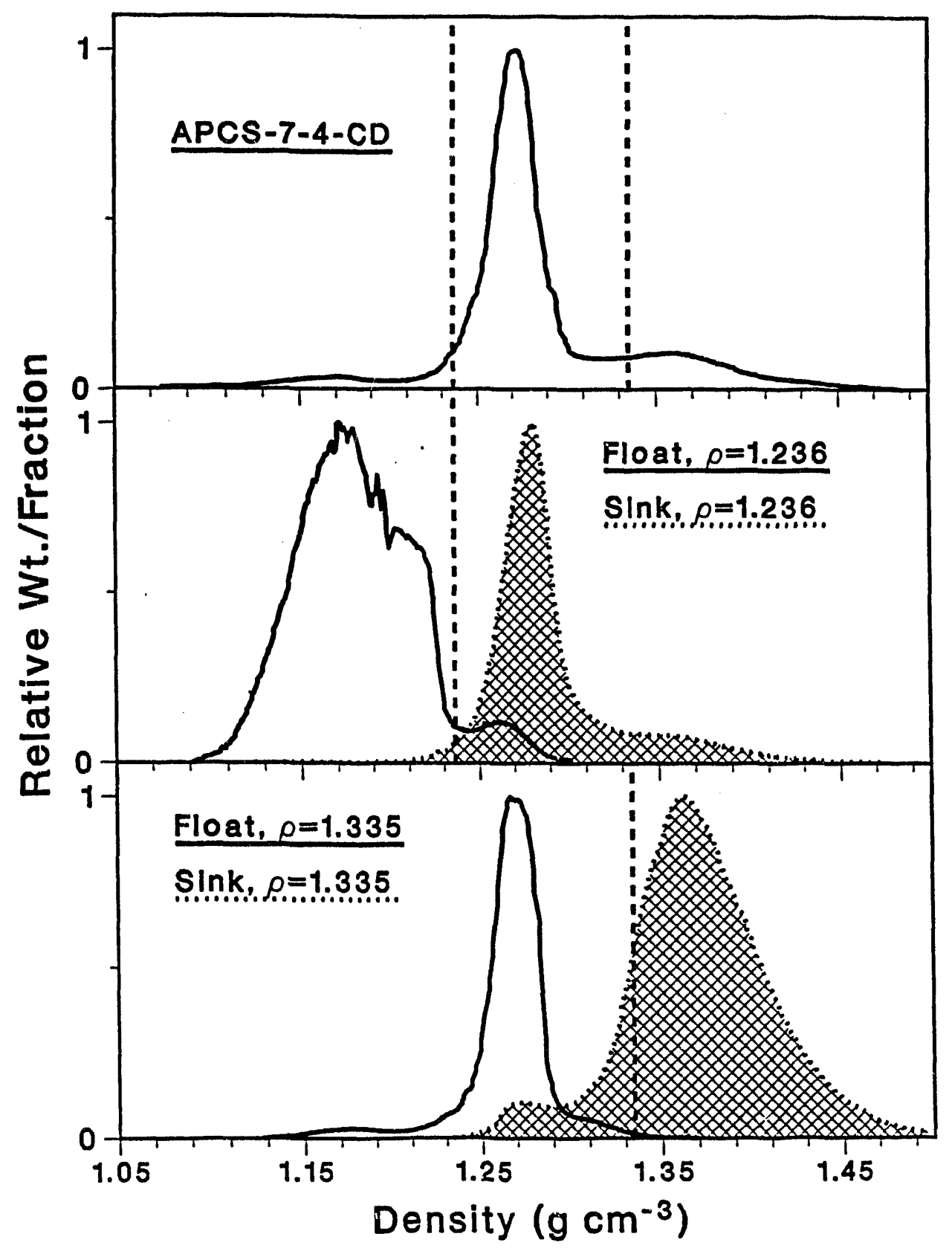

Figure 1. Continuous flow separation of high volatile bituminous coal from Lewiston-Stockton seam, WV, at two densities. Top: density distribution of the original coal. Middle: normalized distributions of float (open) and sink (crosshatch) phases at $1.236 \mathrm{~g} \mathrm{~cm}^{-3}$. Bottom: normalized distributions of float (open) and sink (crosshatch) phases at $1.335 \mathrm{~g} \mathrm{~cm}^{-3}$. Vertical bars represent the density of the CF separations. The amount of impurity for the float distributions is the area of the curve to the right of the vertical line, the reverse is true for the sink phases. 

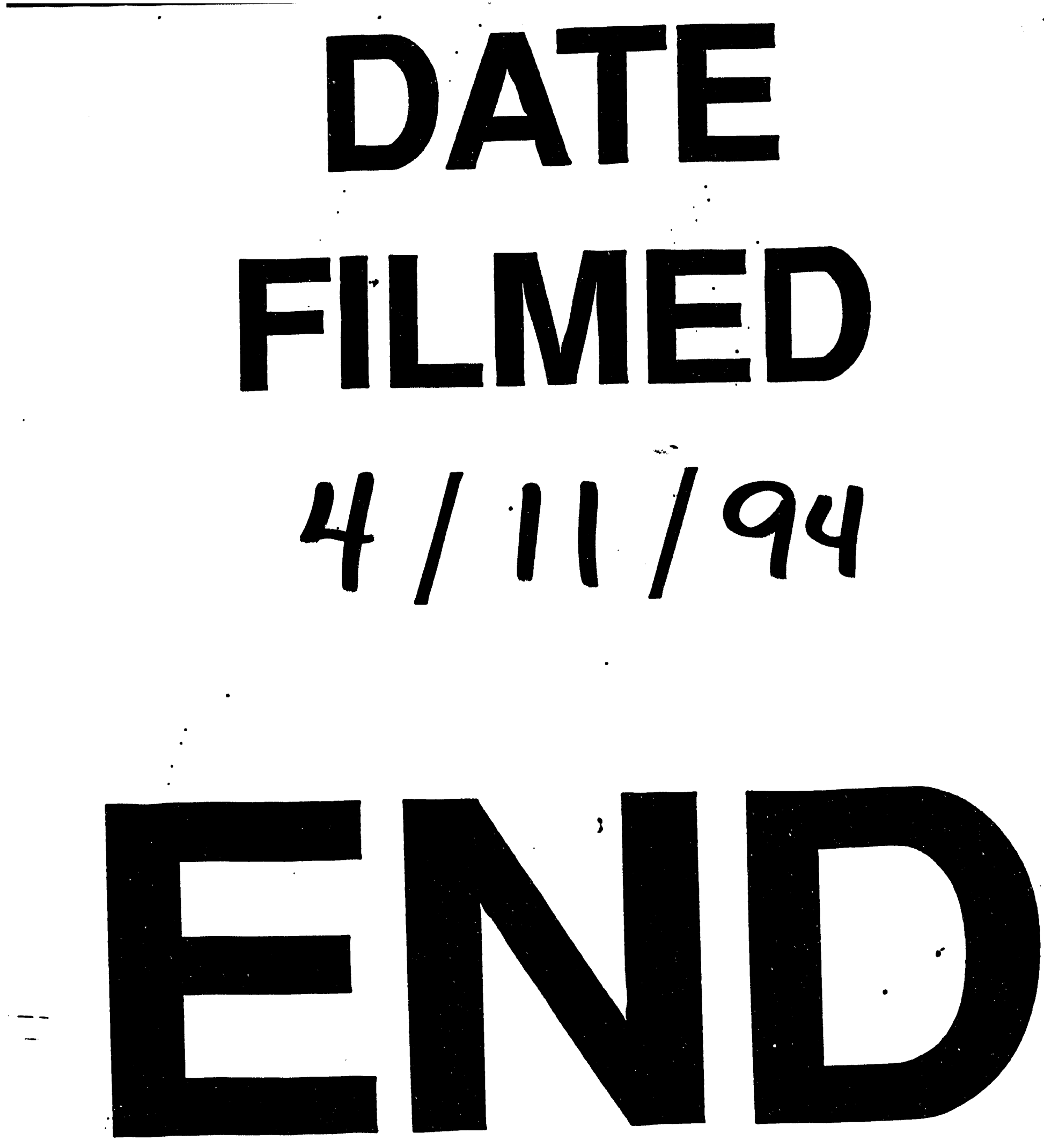
1.

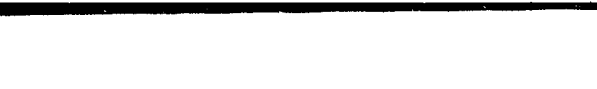

